\title{
Two-year results after convective radiofrequency water vapor thermal therapy of symptomatic benign prostatic hyperplasia
}

This article was published in the following Dove Press journal:

Research and Reports in Urology

21 November 2016

Number of times this article has been viewed

\author{
Christopher M Dixon' \\ Edwin Rijo Cedano ${ }^{2}$ \\ Dalibor Pacik ${ }^{3}$ \\ Vítězslav Vit $^{3}$ \\ Gabriel Varga ${ }^{3}$ \\ Lennart Wagrell ${ }^{4}$ \\ Thayne R Larson ${ }^{5}$ \\ Lance A Mynderse ${ }^{6}$
}

'Department of Urology, Phelps Memorial Hospital, Sleepy Hollow, New York, NY, USA; ${ }^{2}$ Department of Urology, Clinical Canela, La Romana, Dominican Republic; ${ }^{3}$ Department of Urology, Brno University Hospital, Brno, Czech Republic;

${ }^{4}$ Urologcentrum, Stockholm, Sweden; ${ }^{5}$ Institute of Medical Research, Scottsdale, AZ, ${ }^{6}$ Department of Urology, Mayo Clinic, Rochester, MN, USA
Correspondence: Christopher M Dixon Department of Urology, Phelps Memorial Hospital, 777 North Broadway, Suite 203, Sleepy Hollow, NY 1059I, USA

Email cdixon3879@aol.com
Objective: The objective of this study was to assess the effectiveness and safety of convective radiofrequency $(\mathrm{RF})$ water vapor thermal therapy in men with lower urinary tract symptoms (LUTS) associated with benign prostatic hyperplasia (BPH); a pilot study design with 2-year follow-up evaluations.

Patients and methods: Men aged $\geq 45$ years with an International Prostate Symptom Score $\geq 13$, a maximum urinary flow rate $\left(\mathrm{Q}_{\max }\right) \leq 15 \mathrm{~mL} / \mathrm{s}$, and prostate volume $20-120 \mathrm{cc}$ were enrolled in a prospective, open-label pilot study using convective RF water vapor energy with the Rezūm System. Patients were followed up for 2 years after transurethral thermal treatment at 3 international centers in the Dominican Republic, Czech Republic, and Sweden. The transurethral thermal therapy utilizes radiofrequency to generate wet thermal energy in the form of water vapor injected through a rigid endoscope into the lateral lobes and median lobe as needed. Urinary symptom relief, urinary flow, quality of life (QOL) impact, sexual function, and adverse events (AEs) were assessed at 1 week, 1, 3, 6, 12, and 24 months.

Results: LUTS, flow rate, and QOL showed significant improvements from baseline; prostate volumes were appreciably reduced. Sexual function was maintained and no de novo erectile dysfunction occurred. The responses evident as early as 1 month after treatment remained consistent and durable over the 24 months of study. Early AEs were typically transient and mild to moderate; most were related to endoscopic instrumentation. No procedure related to late AEs were seen.

Conclusion: The Rezūm System convective RF thermal therapy is a minimally invasive treatment for BPH/LUTS which can be performed in the office or as an outpatient procedure with minimal associated perioperative AEs. It has no discernable effect on sexual function and provides significant improvement of LUTS that remain durable at 2 years.

Keywords: benign prostatic hyperplasia, lower urinary tract symptoms, convective RF, water vapor thermal therapy, minimally invasive

\section{Introduction}

Benign prostatic hyperplasia (BPH) is a common chronic condition often associated with progressive development of lower urinary tract symptoms (LUTS). Bother of symptoms increases in severity with increasing age. ${ }^{1,2}$ The health care costs for BPH are included in the 10 most prominent and costly diseases in men $>50$ years of age in the United States. ${ }^{3}$ The personal and economic burdens of illness associated with BPH/ LUTS in the United Kingdom have been reviewed. ${ }^{4}$ The global prevalence of LUTS/ $\mathrm{BPH}$, impact on patients and their partners, and societal costs of this condition have been well described. ${ }^{1,4-7}$ Despite the availability of a variety of established and wellstudied treatments, most men are reluctant to undergo a major surgical procedure due to 
the inherent risks and changes in sexual function. Many men initiate medical therapy but have inadequate improvement in their symptoms and quality of life (QOL) or experience undesirable side effects that lead to discontinuation. Increasingly, men do not want to commit to lifetime pharmaceutical treatment often with multiple drugs.

Minimally invasive treatments, including conductively delivered electromagnetic energy heat therapies such as transurethral needle ablation (TUNA) and transurethral microwave thermotherapy (TUMT), provide clinicians with other options in the continuum between medical management and surgical approaches. The limitations, tolerability, and safety of these treatments have been assessed..$^{8,9}$ These minimally invasive options for BPH have not been widely adopted by the urologic community.

Convective RF water vapor energy (Rezūm System; NxThera, Inc., Maple Grove, MN, USA) was introduced as a minimally invasive, radiofrequency thermal energy-based treatment, designed to convectively deliver sterile water vapor, or steam for targeted ablation limited to the transition and central zones in men with clinical BPH. ${ }^{10-12}$ The objective of this report was to assess the 2-year clinical outcomes in the first patients treated with this new technology. This pilot study examined the methods and procedures to evaluate the preliminary effectiveness and safety of treatment in preparation for a larger scale randomized clinical trial with a comparative sham/control procedure. None of the patients reported herein are included in the randomized, multicenter, blinded trial reported elsewhere. ${ }^{13}$

\section{Patients and methods}

A prospective, nonrandomized pilot study of thermal therapy using convective RF water vapor thermal therapy was conducted in 3 international clinical centers: the Dominican Republic, Czech Republic, and Sweden. Men with moderate to severe LUTS secondary to BPH were screened, provided written informed consent, and were enrolled in the trial. Patients were scheduled to be followed annually for 5 years.

Eligible patients were aged $\geq 45$ years and had no prior minimally invasive or surgical interventions for BPH. They underwent washout of antihistamines, antispasmodics (1 week; except with documented evidence of stable dosing for last 6 months), $\alpha$-blockers, androgens, gonadotropin-releasing hormone analogs ( 2 weeks), $5 \alpha$-reductase inhibitors (6 months), and use of antidepressants, anticholinergics, anticonvulsants, ß-blockers (unless with documented evidence of stable dosing).

Inclusion criteria included prostate volume $20-120 \mathrm{cc}$, International Prostate Symptom Score (IPSS) $\geq 13$, peak urinary flow rate $\left(\mathrm{Q}_{\max }\right) \leq 15 \mathrm{~mL} / \mathrm{s}$ with a voided volume $\geq 125 \mathrm{~mL}$, and post-void residual volume (PVR) $<300 \mathrm{~mL}$. Exclusion criteria included confirmed or suspected prostate or bladder cancer and active urinary tract infection or bacterial prostatitis within the last year. Importantly, subjects with a median lobe were not excluded and could be treated at the discretion of the physician investigator. The study protocol was approved by the Institutional Ethics Review Committees at each study center and performed in keeping with Good Clinical Practices and ethical standards of the 1964 Declaration of Helsinki and its later amendments (NCT02940392 and NCT02943070).

\section{Study endpoints}

Subject self-administered questionnaires were completed prior to the procedure and at follow-up visits conducted at 1 week, 1, 3, 6, 12, and 24 months after convective RF thermal therapy. These included the IPSS, QOL instruments (QOL from IPSS, BPHII), and sexual function with the International Index of Erectile Function (IIEF), the IIEF-question 9 for ejaculatory function, and the Male Sexual Health Questionnaire for Ejaculatory Dysfunction (MSHQ-EjD) (1 center). Uroflowmetry, PVR, and prostate specific antigen (PSA) were repeated at 1 week, 1, 3, 6, 12, and 24 months. An independent urologist adjudicated all reported adverse events (AEs). AEs related to device and/or the procedures were evaluated with the Clavien-Dindo classification at each study center. A retrospective review of all AEs was conducted at the conclusion of the study by the Clinical Events Committee for an ongoing randomized, controlled trial to ensure consistency between the pilot and pivotal studies and reporting for publication.

\section{Statistical methods}

Descriptive statistics were used to describe the baseline and follow-up values for all study parameters (IPSS, QOL, BPHII, $Q_{\max }$, PVR, IIEF, and MSHQ-EjD). Where stated, values are reported as the mean (standard deviation, SD), and $95 \%$ confidence intervals or $\mathrm{n}(\%)$. The change from baseline for this longitudinal analysis was compared using a paired Student's $t$-test for each measure. The total IPSS and percent improvement for patients with moderate (IPSS $\leq 18$ ) and severe (IPSS $\geq 19$ ) LUTS, and the changes in storage and voiding symptoms throughout the 2-year follow-up after treatment were calculated. A $P$-value $<0.05$ indicated statistical significance.

\section{Principles of the ablative characteristics of convective RF water vapor thermal energy}

The principles of convective RF water vapor thermal energy are based on the thermodynamic properties of water and the 
use of convective versus conductive heat transfer to ablate tissue. Transurethral convective thermal therapy utilizes RF to generate wet thermal energy in the form of water vapor (steam). As the vapor is convectively dispersed through the tissue interstices, it phase shifts from vapor back to liquid almost immediately upon injection into the tissue releasing and delivering $\sim 208 \mathrm{cal}$ of thermal energy in $9 \mathrm{~s}$. The resultant tissue temperature of $\sim 70^{\circ} \mathrm{C}$ results in irreversible and near instantaneous cell death, creating a roughly spherical ablative lesion of $\sim 1.5-2 \mathrm{~cm} .{ }^{12}$ This convective heat transfer, or vapor physically moving through the tissue, involves virtually no discernible thermal gradient as seen with conductive heat transfer technologies (e.g., TUNA, TUMT). Because vapor has mass and is physically less dense than the compartmental barriers of the prostate (surgical capsule, true capsule, urethra, bladder neck, and external sphincter), it remains within the transition zone when injected there. No thermal effects occur outside of the prostate or in the peripheral zone when the transition zone is targeted. In addition, because vapor is wet thermal energy, there is no charring, desiccation, or carbonization of the treated tissue.

In comparison, tissue ablation via heat transfer by conduction (TUNA or TUMT) induces molecular agitation within a tissue mass after direct contact between two surfaces at different temperatures thereby causing a thermal gradient. Thus, higher temperatures and longer periods of heating are required to achieve a therapeutic temperature in the target tissue via conduction versus convection. Because of the thermal properties of conductive heating, ablative therapies based on conduction do not respect natural tissue boundaries within the prostate.

The rapid and efficient delivery of thermal energy with the convective RF water vapor energy utilizes fewer joules per gram of tissue, $\sim 1 / 6$ to $1 / 23$, to produce cell necrosis in hyperplastic prostate tissue when compared to other traditional thermal ablation methods, TUNA and TUMT, respectively. ${ }^{14}$

\section{Study procedure for convective RF water vapor thermal therapy}

Initial thermal treatment procedures in this pilot study evolved with slight modifications to optimize the water vapor delivery and endoscopic technique. ${ }^{11}$ These modifications in dosimetry and technique were guided by serial gadolinium-enhanced magnetic resonance imaging (MRI) performed after the thermal therapy in 59 of the 65 patients in this study at each of the scheduled follow-up visits through 6 months. ${ }^{12}$ Early characterization of thermal ablation had been identified in a study involving histological examination of convective RF water vapor thermal therapytreated prostates in patients previously scheduled for surgical removal of the prostate. ${ }^{10}$

The procedure was performed utilizing the Rezūm System previously described in detail. ${ }^{10-13}$ Briefly, water vapor thermal energy is created with RF current against an inductive coil heater in the handle of the device. The device delivers water vapor $\left(103^{\circ} \mathrm{C}\right)$ with a consistent energy dose of $208 \mathrm{cal}(1 \mathrm{cal}=4.2 \mathrm{~J})$ through a retractable needle and saline flush irrigation to enhance visualization and cool the urethral surface. The total length of the vapor needle that penetrates prostate tissue is fixed at $10.25 \mathrm{~mm}$. The delivery device tip is initially positioned $\sim 1 \mathrm{~cm}$ distal to the bladder neck. The vapor needle is deployed and a 9-s delivery of water vapor $(0.5 \mathrm{~mL})$ is injected and disperses circumferentially. The vapor needle is retracted after each injection and repositioned $\sim 1 \mathrm{~cm}$ distal from the previous treatment site to the proximal edge of the verumontanum. The objective of the treatment is to create contiguous, overlapping lesions running parallel to the natural slope of the urethra (Figure 1). The treatment can be customized to the configuration of the gland including the median lobe. All investigators were mentored in the use of the Rezūm System in order to implement standardized treatment procedures with identical devices.

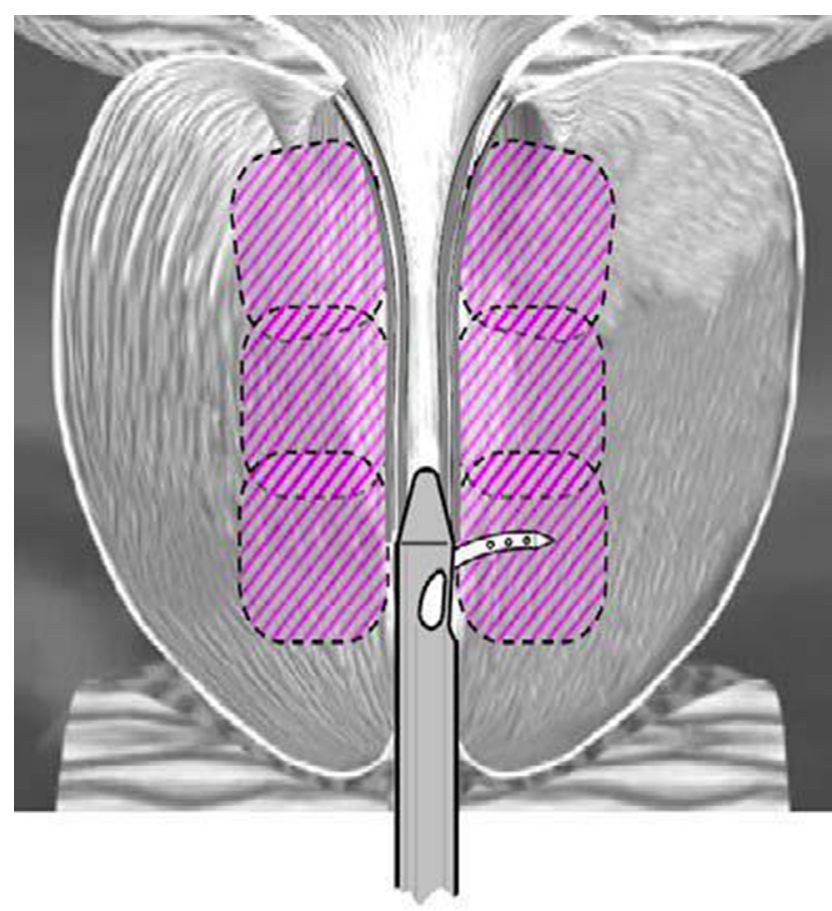

Figure I Schematic of contiguous ablation zones in the prostate after convective RF water vapor thermal therapy; example shows 3 treatments per side. 


\section{Results}

\section{Baseline characteristics and patient follow-up}

Baseline demographics and characteristics of the 65 men treated with convective RF water vapor thermal therapy are included in Table 1. Moderate LUTS was reported in 32.3\%

Table I Baseline demographics and characteristics of subjects enrolled

\begin{tabular}{|c|c|c|}
\hline Characteristic & Mean (SD, range) & $\mathbf{N}$ \\
\hline Age, years & $66.6(7.7,50.0-90.0)$ & 65 \\
\hline Prostate volume, cc & $48.6(20.5,19.5-110.4)$ & 65 \\
\hline PSA, ng/mL & $3.9(4.2,0.2-20.3)$ & 65 \\
\hline IPSS* - all subjects & $21.6(5.5,13.0-35.0)$ & 65 \\
\hline \multicolumn{2}{|l|}{ LUTS severity, n (\%) [range] } & 65 \\
\hline Moderate (IPSS $\leq 18)[13-18]$ & $21 / 65(32.3 \%)$ & \\
\hline Severe (IPSS $\geq 19)$ [19-35] & $44 / 65$ (67.7\%) & \\
\hline QOL (question 8 of IPSS) & $4.3(1.1,0.0-6.0)$ & 65 \\
\hline BPHII & $6.8(2.8,0.0-13.0)$ & 64 \\
\hline $\mathrm{Q}_{\max }, \mathrm{mL} / \mathrm{s}$ & $7.9(3.2,1.4-15.0)$ & 65 \\
\hline PVR, mL & $92.4(77.3,0.0-300.0)$ & 63 \\
\hline \multicolumn{3}{|l|}{ Ethnicity, n (\%) } \\
\hline Caucasian & $46 / 65$ (70.8\%) & \\
\hline Black or African origin & $2 / 65(3.1 \%)$ & \\
\hline Hispanic or Latino & $17 / 65(26.2 \%)$ & \\
\hline History of ED, n (\%) & $24 / 50(48.0 \%)$ & 50 \\
\hline History of retrograde ejaculation & $4 / 50(8.0 \%)$ & 50 \\
\hline IIEF-I5 - all subjects & $34.4(25.4,5.0-73.0)$ & 61 \\
\hline \multicolumn{3}{|l|}{ (total score range $0-75$ ) } \\
\hline \multicolumn{2}{|l|}{ IIEF-erectile function, severity score } & 64 \\
\hline \multicolumn{3}{|l|}{ [range], n (\%) } \\
\hline Normal $[\geq 26-30]$ & $19 / 64$ (29.7\%) & \\
\hline Mild [I $7 \leq$ IIEF-EF $\leq 25]$ & $9 / 64(14.1 \%)$ & \\
\hline Moderate $[I I \leq I I E F-E F \leq 16]$ & $5 / 64(7.8 \%)$ & \\
\hline Severe $[I \leq I I E F-E F \leq 10]$ & $31 / 64(48.4 \%)$ & \\
\hline \multicolumn{3}{|l|}{ IIEF-question 9 (score range 0-5) } \\
\hline \multirow{3}{*}{\multicolumn{3}{|c|}{$\begin{array}{l}\text { "When you had sexual stimulation } \\
\text { or intercourse, how often did you } \\
\text { ejaculate?" }\end{array}$}} \\
\hline & & \\
\hline & & \\
\hline Continuous (all subjects' scores) & $2.2(2.3,0.0-5.0)$ & 65 \\
\hline No sexual stimulation & $29 / 65(44.6 \%)$ & \\
\hline Almost never or never & $2 / 65(3.1 \%)$ & \\
\hline $\begin{array}{l}\text { A few times (much less than half the } \\
\text { time) }\end{array}$ & $6 / 65(9.2 \%)$ & \\
\hline Sometimes (about half the time) & $2 / 65(3.1 \%)$ & \\
\hline $\begin{array}{l}\text { Most times (much more than half the } \\
\text { time) }\end{array}$ & $5 / 65$ (7.7\%) & \\
\hline Almost always or always & $21 / 65$ (32.3\%) & \\
\hline MSQH-EjD function (score range $0-15$ ) & $5.9(4.8,1.0-13.0)$ & $14^{\dagger}$ \\
\hline MSQH-EjD bother (score range $0-5$ ) & $2.3(2.3,0.0-5.0)$ & $14^{\dagger}$ \\
\hline
\end{tabular}

Notes: *IPSS score range 0 (no symptoms) to 35 (maximal symptoms).

tQuestionnaire administered in only I study center; the other 2 centers utilized IIEF-question 9 to assess ejaculatory function.

Abbreviations: SD, standard deviation; PSA, prostate specific antigen; IPSS, International Prostate Symptom Score; LUTS, lower urinary tract symptoms; QOL, quality of life; BPHII, benign prostatic hyperplasia impact index; $\mathrm{Q}_{m a x}$, peak urinary flow; PVR, post-void residual volume; ED, erectile dysfunction; IIEF-EF, International Index of Erectile Function-Erectile Function; EF, erectile function domain; MSHQEjD, Male Sexual Health Questionnaire for Ejaculatory Dysfunction (EjD), function (sum of force, volume, frequency questions). and severe LUTS in $67.7 \%$ of patients. A history of concurrent erectile dysfunction (ED) was noted in $48 \%$.

Over the 2-year follow-up of the 65 subjects, 58 (89.2\%) were accounted for at 1 year and $43(66.2 \%)$ at 2 years. In the first 12 months, 7 subjects did not complete the study; lost to follow-up (3), relocation (2), or poor health (2) including one with previously undiagnosed prostate cancer eventuating in a radical prostatectomy. In the $12-$ to 24 -month period, 15 subjects exited from the study because they missed the 24-month follow-up (2), died (2), other treatment (2, open prostatectomy, TURP), lost to follow-up (4), or had a second phase of treatment with convective RF water vapor thermal therapy (5). Concomitant therapy with drugs for LUTS was not permitted; however, 4 patients did receive BPH medication 1-4 months after the thermal therapy for relief of intermittent or residual LUTS. One additional patient commenced use of a phosphodiesterase type 5 inhibitor at 1 year after treatment. There was no discernible or consistent pattern of effects attributable to any medical therapy.

\section{Procedure}

All procedures were successfully performed without perioperative serious device or procedure related AEs. The mean total number of water vapor injections to lateral lobes was 4.6 (range, $2-9$ injections). The median lobe was treated in 14 patients with a mean of 1.8 water vapor injections (range, 1-3 injections). Investigators used varying combinations of pain and anxiety management based on their clinical judgment and standard of practice. Of the 65 subjects, 51 (78.5\%) received oral medications only for sedation and 14 (20.9\%) had intravenous sedation.

Some patients $(36 / 65,55 \%)$ were catheterized before discharge at the discretion of the investigator (precautionary catheter use; 15), or for inadequate voiding (14), hematuria (6), or dysuria (1), events often associated with rigid cystoscopy. The median duration of catheter use was 4.1 days. An additional 11 patients (17\%) were catheterized after discharge for a median of 3.8 days related to urinary retention or travel convenience. ${ }^{11}$ No patient had urinary retention requiring catheterization in the follow-up period from 12 to 24 months.

\section{Effectiveness}

The convective RF thermal therapy showed clinically and statistically significant improvements in IPSS, QOL, BPHII, and $Q_{\max }$ throughout the course of the 2-year study (Table 2). IPSS change from baseline was the primary effectiveness outcome measure. A significant reduction of -6.5 points in IPSS was achieved as early as at 1 month, $P<0.001$; the mean change of -12.5 points $(56 \%)$ at 12 months was durable at 
Table 2 Baseline, follow-up, and change in each outcome measure after convective RF water vapor thermal therapy

\begin{tabular}{|c|c|c|c|c|c|c|}
\hline Outcome measure & I week & I month & 3 months & 6 months & 12 months & 24 months \\
\hline \multicolumn{7}{|l|}{ IPSS } \\
\hline $\mathrm{N}$ (paired values) & & 64 & 62 & 62 & 58 & 43 \\
\hline Baseline & & $21.6(5.5)$ & $21.7(5.5)$ & $21.6(5.6)$ & $21.7(5.7)$ & $21.7 \pm 5.3$ \\
\hline Follow-up & & | $4.8(8.4)$ & $8.3(5.8)$ & $8.5(7.0)$ & $9.2(6.5)$ & $9.6 \pm 6.5$ \\
\hline Change & & $-6.8(10.0)$ & $-13.4(7.6)$ & $-13.1(8.6)$ & $-12.5(7.6)$ & $-12.1 \pm 7.9$ \\
\hline$P$-value & & $<0.001$ & $<0.001$ & $<0.001$ & $<0.001$ & $<0.00$ I \\
\hline \multicolumn{7}{|c|}{ QOL, IPSS-question 8) } \\
\hline $\mathrm{N}$ (paired values) & 64 & 64 & 62 & 62 & 58 & 43 \\
\hline Baseline & $4.3(1.1)$ & $4.3(1.1)$ & $4.3(1.1)$ & $4.3(1.1)$ & $4.4(1.1)$ & $4.4(1.2)$ \\
\hline Follow-up & $3.6(1.8)$ & $2.9(1.8)$ & $1.5(1.4)$ & $1.6(1.6)$ & $1.7(1.4)$ & $1.8(1.4)$ \\
\hline Change & $-0.8(1.8)$ & $-1.5(2.0)$ & $-2.8(1.6)$ & $-2.7(2.0)$ & $-2.7(1.6)$ & $-2.6(1.7)$ \\
\hline$P$-value & $<0.001$ & $<0.001$ & $<0.001$ & $<0.001$ & $<0.001$ & $<0.001$ \\
\hline \multicolumn{7}{|l|}{ BPHII } \\
\hline $\mathrm{N}$ (paired values) & & 62 & 61 & 59 & 56 & 42 \\
\hline Baseline & & $6.8(2.9)$ & $6.8(2.9)$ & $6.8(2.9)$ & $6.9(2.8)$ & $7.1(2.7)$ \\
\hline Follow-up & & $5.5(3.6)$ & $2.2(2.4)$ & $2.0(2.6)$ & $2.0(2.3)$ & $2.3(2.5)$ \\
\hline Change & & $-1.2(4.4)$ & $-4.7(3.2)$ & $-4.8(3.7)$ & $-4.9(3.0)$ & $-4.8(3.5)$ \\
\hline$P$-value & & 0.034 & $<0.001$ & $<0.001$ & $<0.001$ & $<0.001$ \\
\hline \multicolumn{7}{|l|}{$Q_{\max }(\mathrm{mL} / \mathrm{s})$} \\
\hline N (paired values) & 61 & 63 & 61 & 60 & 57 & 39 \\
\hline Baseline & $8.1(3.1)$ & $7.9(3.2)$ & $8.1(3.2)$ & $8.0(3.1)$ & $8.1(3.3)$ & $8.3(2.8)$ \\
\hline Follow-up & $7.6(3.9)$ & $9.9(3.9)$ & $12.8(6.4)$ & $12.3(5.3)$ & $12.7(6.3)$ & $12.0(6.2)$ \\
\hline Change & $-0.5(4.2)$ & $2.0(4.5)$ & $4.7(6.4)$ & $4.3(5.5)$ & $4.6(6.4)$ & $3.7(6.5)$ \\
\hline$P$-value & 0.989 & $<0.001$ & $<0.001$ & $<0.001$ & $<0.001$ & 0.001 \\
\hline \multicolumn{7}{|l|}{ PVR } \\
\hline $\mathrm{N}$ (paired values) & 61 & 62 & 60 & 58 & 55 & 38 \\
\hline Baseline & 90.7 (77.9) & 92.1 (77.9) & $89.5(77.3)$ & $87.3(74.2)$ & $92.2(78.4)$ & $78.5(65.8)$ \\
\hline Follow-up & $117.6(125.2)$ & $67.1(64.4)$ & $59.6(66.4)$ & $65.9(88.5)$ & $64.5(72.3)$ & $62.8(83.9)$ \\
\hline Change & $26.7(131.1)$ & $-25.0(92.3)$ & $-29.9(78.0)$ & $-21.4(88.3)$ & $-27.6(82.9)$ & $-15.6(93.1)$ \\
\hline$P$-value & 0.117 & 0.037 & 0.004 & 0.071 & 0.017 & 0.307 \\
\hline \multicolumn{7}{|l|}{ IIEF-EF } \\
\hline $\mathrm{N}$ (paired values) & & 60 & 58 & 59 & 55 & 31 \\
\hline Baseline & & I3.3 (12.0) & I2.8(II.8) & $13.5(12.0)$ & $12.6(\mid 1.7)$ & $11.8(12.4)$ \\
\hline Follow-up & & $10.3(11.6)$ & I4.5 (II.9) & I5.4 (I2.0) & |4.| (II.8) & I5.5 (I I.5) \\
\hline Change & & $-3.0(9.8)$ & $1.7(10.1)$ & $1.9(8.9)$ & I.5 (8.7) & $3.6(6.8)$ \\
\hline$P$-value & & 0.019 & 0.201 & 0.102 & 0.210 & 0.006 \\
\hline \multicolumn{7}{|l|}{ IIEF-question 9} \\
\hline $\mathrm{N}$ (paired values) & & 64 & 62 & 60 & 58 & 33 \\
\hline Baseline & & $2.2(2.2)$ & $2.2(2.2)$ & $2.2(2.2)$ & $2.1(2.2)$ & $2.1(2.3)$ \\
\hline Follow-up & & $1.8(2.3)$ & $2.9(2.3)$ & $2.6(2.3)$ & $2.6(2.3)$ & $2.7(2.2)$ \\
\hline Change & & $-0.4(2.2)$ & $0.7(2.3)$ & $0.5(1.9)$ & $0.4(1.7)$ & $0.5(1.8)$ \\
\hline$P$-value & & 0.151 & 0.020 & 0.061 & 0.053 & 0.095 \\
\hline \multicolumn{7}{|l|}{ MSHQ-EjD function } \\
\hline $\mathrm{N}$ (paired values) & & 14 & 14 & 13 & 12 & 8 \\
\hline Baseline & & $5.9(4.8)$ & $5.9(4.8)$ & $5.5(4.7)$ & $5.3(4.9)$ & $4.6(5.2)$ \\
\hline Follow-up & & $5.6(6.1)$ & $7.1(5.0)$ & $8.0(4.5)$ & $5.0(4.7)$ & $7.0(4.8)$ \\
\hline Change & & $-0.2(3.9)$ & $1.2(4.6)$ & $2.5(4.9)$ & $-0.3(5.8)$ & $2.4(5.2)$ \\
\hline$P$-value & & 0.841 & 0.339 & 0.085 & 0.884 & 0.234 \\
\hline \multicolumn{7}{|l|}{ MSHQ-EJD bother } \\
\hline $\mathrm{N}$ (paired values) & & 14 & 14 & 13 & 12 & 8 \\
\hline Baseline & & $2.3(2.3)$ & $2.3(2.3)$ & $2.5(2.3)$ & $2.3(2.2)$ & $2.6(2.2)$ \\
\hline Follow-up & & $0.8(0.9)$ & $0.9(I .1)$ & $1.0(0.9)$ & $0.9(0.8)$ & $0.8(0.5)$ \\
\hline Change & & $-1.5(2.7)$ & $-1.4(2.4)$ & $-1.5(2.5)$ & $-1.3(2.3)$ & $-1.9(2.0)$ \\
\hline$P$-value & & 0.057 & 0.055 & 0.060 & 0.071 & 0.035 \\
\hline
\end{tabular}

Note: Each parameter is presented as the mean (SD) and compared with baseline using a paired Student's $t$-test.

Abbreviations: SD, standard deviation; IPSS, International Prostate Symptom Score; QOL, quality of life; BPHII, benign prostatic hyperplasia impact index; ${ }_{\text {max }}$, peak urinary flow; PVR, post-void residual volume; IEF-EF, International Index of Erectile Function-Erectile Function (EF); MSHQ-EjD, Male Sexual Health Questionnaire for Ejaculatory Dysfunction (EjD). 


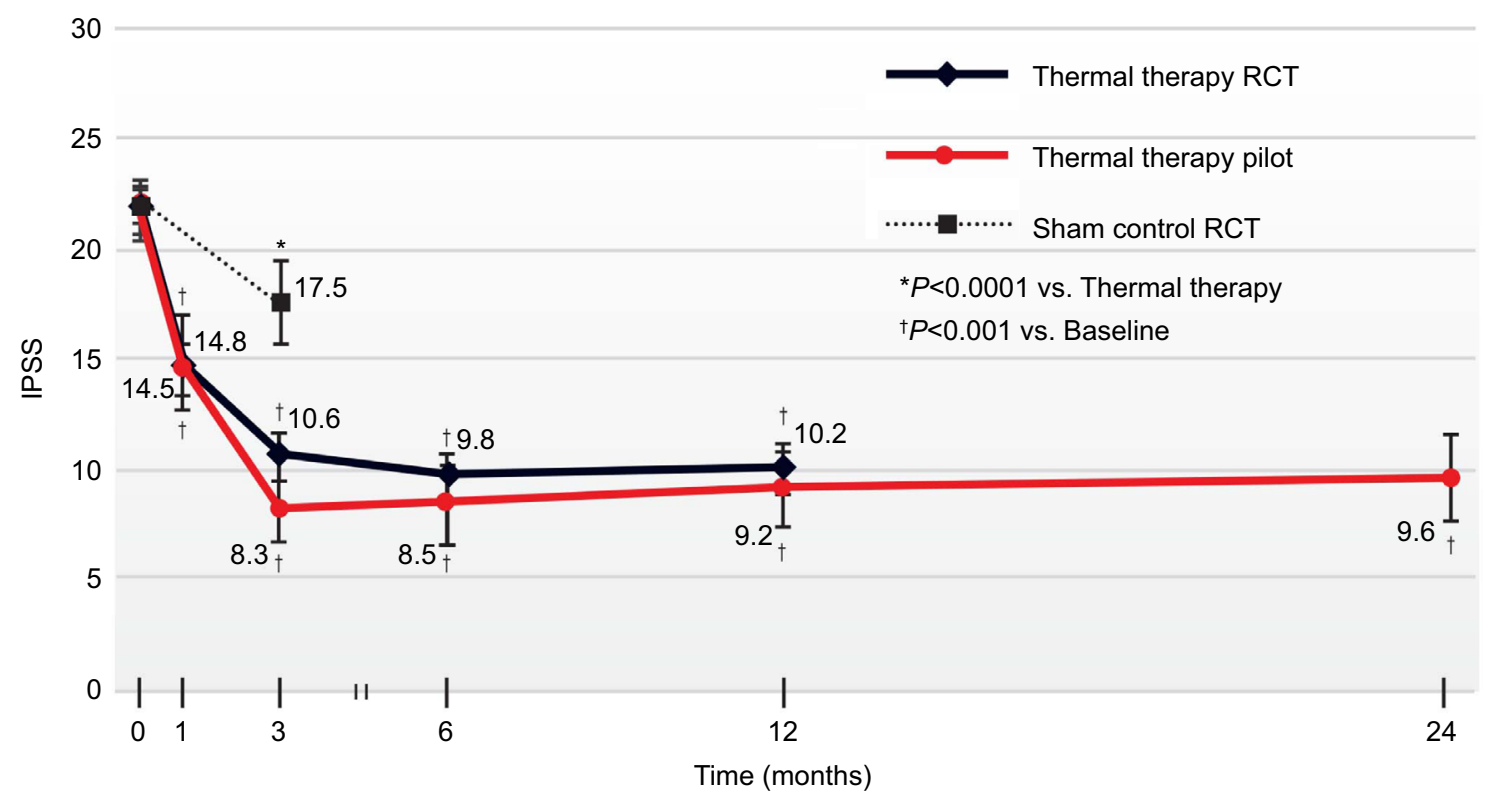

Figure 2 IPSS changes throughout 24 months after convective RF water vapor thermal therapy.

Notes: Also plotted are results from a randomized, blinded, sham controlled trial showing similarity of outcomes over 12 months. Values are the mean absolute IPSS, errors bars represent $95 \% \mathrm{Cl}$.

Abbreviations: IPSS, International Prostate Symptom Score; Cl, confidence interval; RCT, randomized controlled trial.

the same magnitude through 24 months, -12.1 points $(55 \%$ reduction), $P<0.001$. The IPSS reductions documented in this pilot study closely resemble those in a previously published randomized controlled study of convective RF thermal therapy in which mean reductions of $\sim 12$ points $(\geq 50 \%$ ) were documented over 12 months (Figure 2). ${ }^{13}$

Based on criteria used to define IPSS responses in individual patients, $72.6 \%$ of patients had an initial $\geq 50 \%$ score decrease at 3 months after convective RF thermal therapy. This response level exceeds the threshold which is described as a clinically meaningful response; the $\geq 50 \%$ improvements were observed in $60.5 \%$ of patients and sustained through 24 months (Table 3). Responses relative to a $\geq 3$ point and $\geq 5$ point decrease in IPSS were shown in $93 \%$ and $79.1 \%$ of subjects at 24 months, respectively. The percentage of subjects achieving these response levels is comparable to those as early as 3 months after convective RF thermal therapy.

QOL and BPHII significantly improved and reflected improvements in LUTS in these subjects (Table 2). $Q_{\max }$ showed incremental improvements, increasing significantly from a mean (SD) of $8.1(3.1) \mathrm{mL} / \mathrm{s}$ at baseline to 12.7 (6.3) $\mathrm{mL} /$ at 12 months $(P<0.001)$, and the increase remained consistent at $12.0(6.2) \mathrm{mL} / \mathrm{s}$ at 24 months $(P=0.001)$.

Analysis of the IPSS composite categories for both storage (frequency, urgency, nocturia) and voiding (incomplete emptying, intermittency, weak stream, straining to void) symptoms showed significant and durable improvements throughout assessments over 2 years (Figure 3A). The mean
Table 3 Proportion of patients with improvements in IPSS after convective RF water vapor thermal therapy

\begin{tabular}{lll}
\hline Posttreatment & \multicolumn{2}{l}{ IPSS change from baseline } \\
& n/N (\% of patients) & \\
\hline & $\mathbf{2 5} \%$ & $\geq \mathbf{5 0} \%$ \\
3 months & $53 / 62(85.5 \%)$ & $45 / 62(72.6 \%)$ \\
6 months & $55 / 63(87.3 \%)$ & $46 / 63(73.0 \%)$ \\
I year & $48 / 58(82.8 \%)$ & $39 / 58(67.2 \%)$ \\
2 years & $36 / 43(83.7 \%)$ & $26 / 43(60.5 \%)$ \\
& $\geq \mathbf{3}$ Points & $\geq \mathbf{5}$ Points \\
3 months & $56 / 62(90.3 \%)$ & $51 / 62(82.3 \%)$ \\
6 months & $57 / 63(90.5 \%)$ & $53 / 63(84.1 \%)$ \\
I year & $51 / 58(87.9 \%)$ & $47 / 58(81.0 \%)$ \\
2 years & $40 / 43(93.0 \%)$ & $34 / 43(79.1 \%)$ \\
\hline
\end{tabular}

Abbreviation: IPSS, International Prostate Symptom Score.

collective storage symptom scores were decreased by $61 \%$ at 12 months and $56 \%$ at 24 months and the mean voiding symptoms by $69 \%$ at 12 and 24 months $(P<0.001)$. The 7 individual IPSS domain analyses indicated that with the initial exception of frequency and nocturia, the symptoms significantly improved within 1 month after the water vapor therapy $(P<0.05$ to $\leq 0.001)$ (Figure $3 \mathrm{~B}$ ) and were durable. The favorable change from baseline for frequency and nocturia became significant by the 3 -month evaluation and remained so up to 2 years $(P<0.001)$.

Subjects with either moderate (IPSS $\leq 18$ ) or severe (IPSS $\geq 19)$ symptoms both achieved improved scores, $P<0.05$ to $<0.0001$ (Figure 4). The study included 44 subjects (68\%) with severe symptoms, 21 with moderate symptoms. Notably 


\section{A}

15

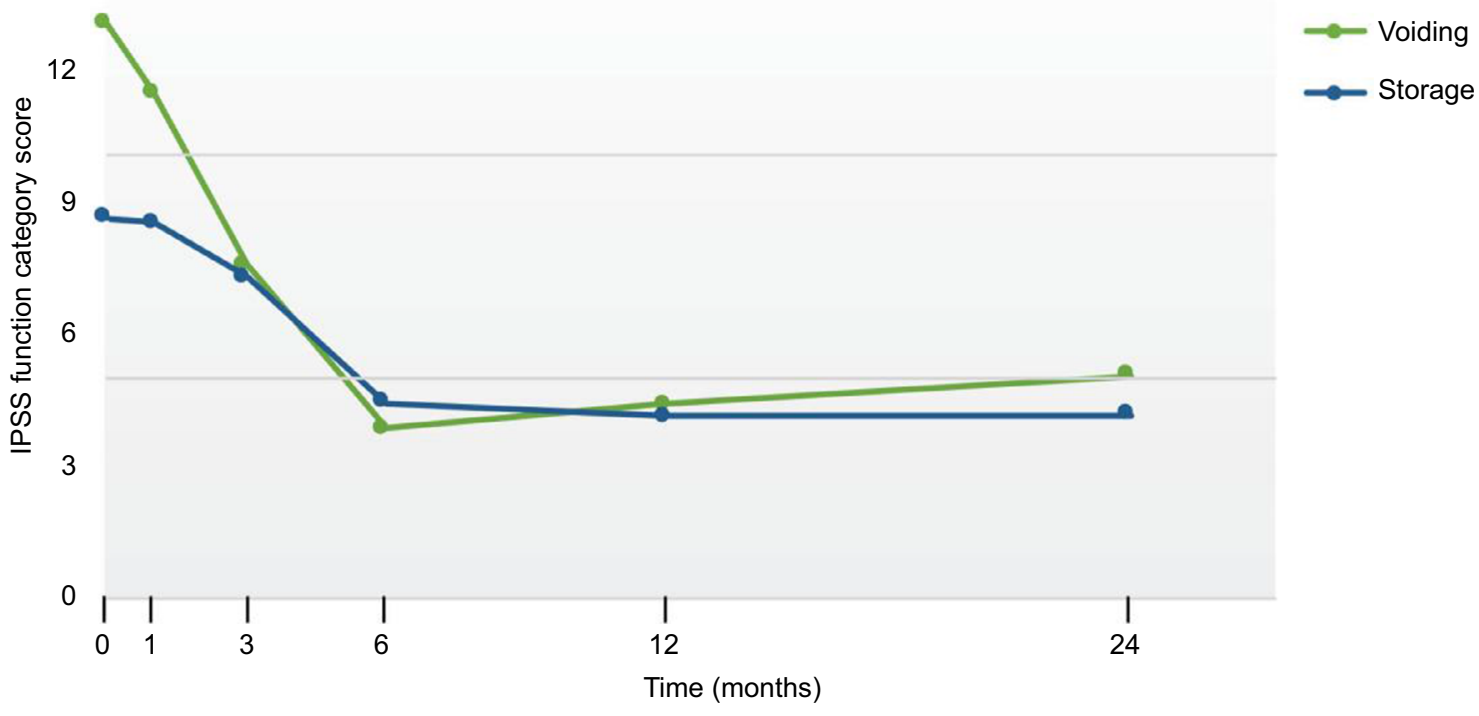

B

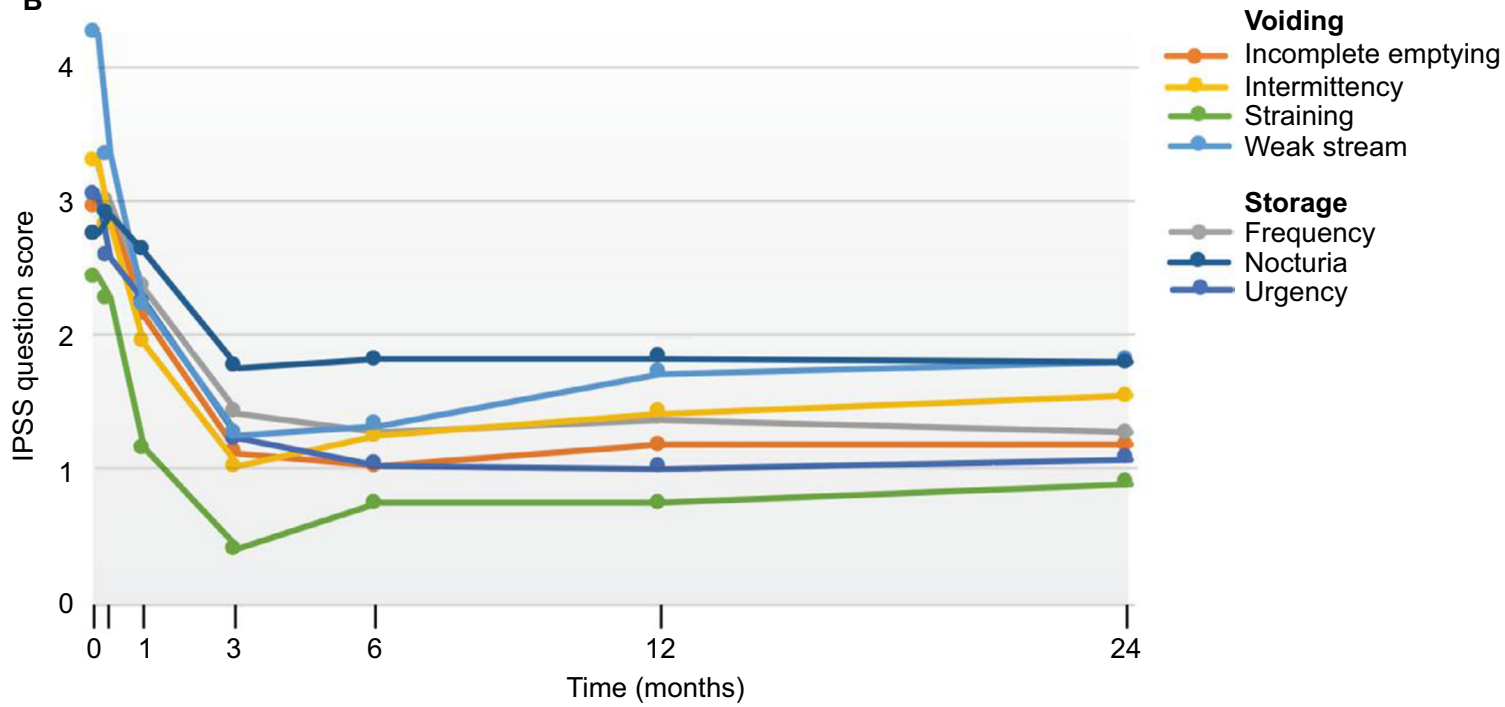

Figure 3 IPSS responses after convective RF water vapor thermal therapy including (A) storage and voiding categories of symptoms and (B) 7 individual question responses. Abbreviation: IPSS, International Prostate Symptom Score.

for the subgroup with severe symptoms, scores decreased to a mean $37.2 \%$ relative to baseline at 1 month ( -9.3 points) and further decreased to a mean $65 \%(-15.8)$ and $60 \%(-14.5)$ at 6 and 12 months, respectively, and remained durable through 24 months, $54 \%$ decrease ( -13.4 points). Subjects with moderate symptoms had mean score decreases of $46 \%$ ( -7.6 points) from 3 to 12 months and sustained in $54 \%$ ( -8.8 points) at 24 months.

No clinically significant changes in sexual function were observed over the 2-year assessments (Table 2). At baseline, $29.7 \%(19 / 64)$ of patients had erectile function (IIEF-EF) scores in the normal range $(\geq 26-30)$. The evaluation of ejaculatory function was limited to the use of the IIEFquestion 9 and revealed that $44.6 \%(29 / 65)$ were not sexually active (reported no sexual stimulation or intercourse) at study enrollment. The MSHQ-EjD was approved for administration at only one study center and hence provided only limited data. As there were no enrollment criteria for sexual function, subjects who were not sexually active for these evaluations were not censored. After treatment, the longitudinal analysis of erectile and ejaculatory functions over 2 years showed a consistent pattern of unchanged scores compared with baseline.

Prostate volumes assessed by gadolinium-enhanced MRI at 1, 3, and 6 months after convective RF thermal therapy 


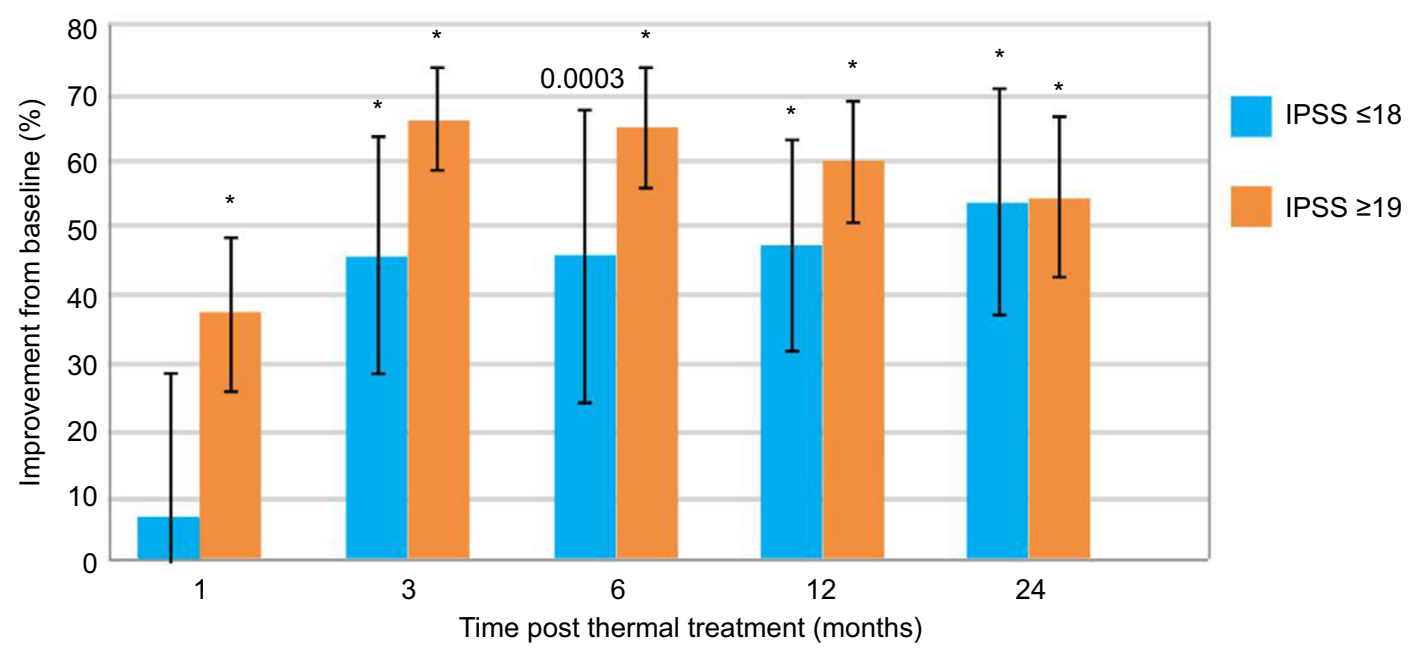

Figure 4 Improvements in IPSS from baseline in patients with moderate and severe LUTS.

Note: $* P<0.0001$ vs baseline.

Abbreviations: IPSS, International Prostate Symptom Score; LUTS, lower urinary tract symptoms.

Table 4 Overview of adjudicated AEs

\begin{tabular}{|c|c|c|c|c|c|c|}
\hline \multicolumn{7}{|c|}{ Events in months post procedure } \\
\hline AEs & $\begin{array}{l}\text { Events* } \\
\mathrm{n}\end{array}$ & $\begin{array}{l}\text { Patients } \\
\text { N (\%) }\end{array}$ & 0-I months & $\begin{array}{l}>I-3 \text { months } \\
n\end{array}$ & $\begin{array}{l}>3-12 \text { months } \\
n\end{array}$ & $\begin{array}{l}>12-24 \text { months } \\
n\end{array}$ \\
\hline Serious AEs related & 3 & $\mathrm{I}(\mathrm{I} .5)$ & I & 0 & 0 & 0 \\
\hline Serious AEs unrelated & 14 & $9(13.8)$ & 4 & I & 6 & 3 \\
\hline \multicolumn{7}{|l|}{ Related non-serious $\mathrm{AE}$} \\
\hline Urinary retention & 24 & $22(33.8)$ & 21 & 2 & I & 0 \\
\hline Dysuria & 14 & $14(2 \mid .5)$ & 9 & 4 & I & 0 \\
\hline Urinary urgency & 14 & $13(20.0)$ & 10 & 4 & 0 & 0 \\
\hline UTI suspected & 13 & $13(20.0)$ & 8 & 4 & I & 0 \\
\hline Hematuria & 10 & $9(13.8)$ & 10 & 0 & 0 & 0 \\
\hline Poor stream & 10 & $9(13.8)$ & 6 & 3 & I & 0 \\
\hline Painful/discomfort - other & 7 & $7(10.8)$ & 5 & 2 & 0 & 0 \\
\hline Nocturia & 6 & $5(7.7)$ & 5 & I & 0 & 0 \\
\hline Urinary frequency & 5 & $4(6.2)$ & 4 & I & 0 & 0 \\
\hline $\begin{array}{l}\text { Urethral secretion - without } \\
\text { hematuria or stones }\end{array}$ & 3 & $3(4.6)$ & 2 & 0 & I & 0 \\
\hline Fever & 3 & $3(4.6)$ & 3 & 0 & 0 & 0 \\
\hline Terminal dribbling & 2 & $2(3.1)$ & 1 & 0 & I & 0 \\
\hline Scrotal pain/discomfort & 2 & $2(3.1)$ & 1 & I & 0 & 0 \\
\hline Urinary incontinence - urge & 2 & $\mathrm{I}(1.5)$ & I & 0 & 0 & 0 \\
\hline
\end{tabular}

Note: *Events occurring in 2 or more patients or $>2 \%$ of the total cohort are presented.

Abbreviations: AE, adverse event; UTI, urinary tract infection.

were significantly decreased at all time points, $P<0.001 .^{12} \mathrm{The}$ volume was reduced by $24 \%$ at month 3 and $30 \%$ at month 6. No clinically meaningful changes in PSA levels occurred throughout the study.

\section{Safety}

AEs related to device and/or procedure were evaluated with the Clavien-Dindo classification. There were no unanticipated AEs in the 125 non-serious events reported in 45 patients. Most (75\%) events were reported within the first 30 days after the procedure. They were mild to moderate transient events,
Clavien-Dindo class I or II, including urinary retention, dysuria, urgency, hematospermia, and suspected urinary tract infection (UTI) that resolved within a few days to 4 weeks (Table 4). Urinary retention was classified as an AE when the duration of inadequate voiding was $>24 \mathrm{~h}$. For the 13 patients being suspected with UTIs, empirical antibiotics were given; no cultures were done. A total of 14 unrelated, serious AEs were reported in 9 patients. One patient had persistent LUTS (poor stream, frequency, and urinary retention) adjudicated as 3 separate device/procedure related grade IIIb events; the median lobe had not been treated. The patient decided 
to undergo a TURP procedure at 42 days. No late occurring device or procedure-related AEs were reported in the 12- to 24-month follow-up. No treatment related de novo ED was reported throughout the 2-year follow-up.

\section{Discussion}

The results from this open-label study of convective RF water vapor thermal therapy are consistent with the recently published results from a randomized study with a similar reduction in IPSS at 1 year ( -11.7 vs. -12.5 points observed in the present study). ${ }^{13}$ This provides evidence of stability and durability for this minimally invasive thermal procedure with a continuing IPSS reduction of 12.1 points at 2 years.

The IPSS improvement of $\geq 50 \%$ throughout the 2 -year follow-up was documented in $\geq 60 \%$ of patients with moderate to severe LUTS, mean baseline IPSS of 21.7 (SD 5.3). These responses exceeded the $\geq 3$ point accepted as being clinically meaningful by the American Urological Association ${ }^{8}$ or the proportion of patients achieving a $\geq 25 \%$ improvement from baseline, classified as responders in drug studies. ${ }^{15,16}$ The convective RF thermal therapy provided symptomatic relief for all 7 IPSS/LUTS domains, and in the composite categories of storage and voiding symptoms (Figure 3 ). These results are associated with $\geq 59 \%$ improvement in the QOL score capturing how troublesome patients find their urinary symptoms, and a $\geq 64 \%$ improvement in the BPHII measuring how much their urinary problems affect various domains of health. The urinary flow improvements after the procedure were statistically significant. $\mathrm{Q}_{\max }$ improvements of $\sim 12.0 \mathrm{~mL} / \mathrm{s}$ were durable throughout 24 months. There was no procedural restriction to the treatment of median lobes, and outcomes were similar in these 14/65 (21.5\%) patients. The magnitudes of these therapeutic changes at 1 year are comparable to those reported in a randomized controlled study of the convective RF water vapor thermal therapy conducted in the United States. ${ }^{13}$

Results presented in this study reflect an excellent safety profile after convective RF water vapor thermal therapy. The early AEs were transient and typical of those following other routine minimally invasive endoscopic procedures. ${ }^{17-19}$ Only 1 patient had serious AEs that were device/procedure related during the first year of follow-up and subsequently underwent a TURP. No late AEs, related to the device or procedure, were reported in the 12- to 24-month follow-up. There was no detectable negative impact on erectile function for those men who began the study with normal erectile function. Otherwise, the assessment of ejaculatory function was limited as the MSHQ was only approved by the ethics committee in one center. It is notable that in the randomized controlled clinical trial of the Rezūm thermal therapy in 136 patients, there was no occurrence of treatment- or device related de novo ED after the procedure. Approximately one-third of the patients, those who were sexually active, had significant improvements in the ejaculatory bother score of the MSHQ after the treatment. ${ }^{20}$

The use of in-dwelling catheterization posttreatment in this study was at the discretion of the investigators $(15 / 35$ subjects or $43 \%$ ) without specific guidelines per protocol or driven by the technology. Thus, the rates of perioperative catheterization may not reflect the actual need but rather a conservative approach after use of a new treatment modality. Catheters were also used by request of patients for convenience during their travels. The necessity for posttreatment catheters remains to be determined with this form of thermal ablation. Urinary retention requiring catheterization did occur in the 1- to 2-year follow-up period.

These data provide valuable insight into this new technology and potential for utilization of convective RF thermal therapy for symptomatic BPH but is limited by the pilot study design, the absence of a control (sham) arm. Analyses of randomized, controlled clinical trials for LUTS/BPH with drugs, endoscopic procedures, and surgeries have shown that placebo effects are to be considered in evaluating the outcomes of active treatments. ${ }^{21,22}$ However, as the improvements in IPSS and $Q_{\max }$ in this study are comparable to those observed in the prospective, controlled pivotal convective RF thermal therapy trial, and similarly durable, ${ }^{13}$ the validity of the therapeutic responses are substantiated.

In conclusion, the durable clinical outcomes of patients treated with convective RF water vapor thermal therapy and followed up for 2 years are reported in this pilot study. This is the first-in-man study utilizing RF energy to create water vapor, or steam, to convectively deliver targeted thermal energy to the transition zone of the prostate. This minimally invasive therapeutic option is a procedure that can be performed in the office or as an outpatient procedure and provides statistically significant improvement in LUTS symptoms, urinary flow, and QOL for patients with symptomatic BPH.

Looking forward, because the convective RF thermal therapy procedure can be performed with minimal anesthesia or physiologic impact, which has only transient mild adverse effects, seemingly no negative impact to sexual function, and considerable improvement in efficacy parameters, one cannot help but consider evaluating convective RF water vapor thermal therapy as a first-line therapy for men with clinical BPH. A well-designed clinical trial to directly compare medical management to convective RF thermal therapy would be intriguing and warrants further consideration. 


\section{Acknowledgment}

The study was funded by NxThera, Inc., Maple Grove, MN, USA.

\section{Disclosure}

Christopher M Dixon and Thayne R Larson have consulted with NxThera in the clinical trial design. Lennart Wagrell has served as a consultant to NxThera for other projects. The authors report no other conflicts of interest in this work.

\section{References}

1. Hutchison A, Farmer R, Chapple C, et al. Characteristics of patients presenting with LUTS/BPH in six European countries. Eur Urol. 2006;50(3):555-561.

2. Parsons JK, Wilt TJ, Wang PY, Barrett-Connor E, Bauer DC, Marshall LM. Progression of lower urinary tract symptoms in older men: a community based study. J Urol. 2010;183(5):1915-1920.

3. Fenter TC, Naslund MJ, Shah MB, Eaddy MT, Black L. The cost of treating the 10 most prevalent diseases in men 50 years of age or older. Am J Manag Care. 2006;12(4 Suppl):S90-S98.

4. Welch G, Weinger K, Barry MJ. Quality-of-life impact of lower urinary tract symptom severity: results from the Health Professionals Follow-up Study. Urology. 2002;59(2):245-250.

5. Rosen R, Altwein J, Boyle P, et al. Lower urinary tract symptoms and male sexual dysfunction: the multinational survey of the aging male (MSAM-7). Eur Urol. 2003;44(6):637-649.

6. Hollingsworth JM, Wei JT. Economic impact of surgical intervention in the treatment of benign prostatic hyperplasia. Rev Urology. 2006;8(Suppl 3);S9-S15.

7. Speakman M, Kirby R, Doyle S, Ioannu C. Burden of male lower urinary tract symptoms (LUTS) suggestive of benign prostatic hyperplasia (BPH) - focus on the UK. BJU Int. 2015;115(4):508-519.

8. American Urological Association Guideline: Management of Benign Prostatic Hyperplasia (BPH); revised March 2010. Available from: http://www.auanet.org/common/pdf/education/clinical-guidance/ Benign-Prostatic-Hyperplasia.pdf. Accessed October 10, 2016.

9. European Association of Urology. Guidelines on the management of non-neurogenic male lower urinary tract symptoms (LUTS) including benign prostatic obstruction (BPO); March 2015. Available from: http://uroweb.org/wp-content/uploads/EAU-Guidelines-Non-Neurogenic-Male-LUTS-Guidelines-2015-v2.pdf. Accessed October 10, 2016.
10. Dixon CM, Cedano ER, Mynderse LA, Larson TR. Transurethral convection water vapor as a treatment for lower urinary tract symptomology due to benign prostatic hyperplasia using the Rezūm ${ }^{\circledR}$ system: evaluation of acute ablative capabilities in the human prostate. Res Rep Urol 2015;7:13-18.

11. Dixon C, Cedano ER, Pacik D, et al. Efficacy and safety of Rezūm system water vapor treatment for lower urinary tract symptoms secondary to benign prostatic hyperplasia. Urology. 2015;86(5):1042-1047.

12. Mynderse LA, Hanson D, Robb RA, et al. Rezūm system water vapor treatment for lower urinary tract symptoms/benign prostatic hyperplasia: Validation of convective thermal energy transfer and characterization with magnetic resonance imaging and 3-dimensional renderings. Urology. 2015;86(1):122-127.

13. McVary KT, Gange SN, Gittelman MC, et al. Minimally invasive prostate convective water vapor energy (WAVE) ablation: a multicenter, randomized, controlled study for treatment of lower urinary tract symptoms secondary to benign prostatic hyperplasia. J Urol. 2016;195(5):1529-1539.

14. Data on file, NxThera, Inc., Maple Grove, MN, USA.

15. Narayan P, Tewari A; Members of the United States 93-01 Study Group. A second phase III multicenter placebo controlled study of 2 dosages of modified release tamsulosin in patients with symptoms of benign prostatic hyperplasia. J Urol. 1998;160(5):1701-1706.

16. Chapple CR, Montorsi F, Tammela TL, et al. Sildosin therapy for lower urinary tract symptoms in men with suspected benign prostatic hyperplasia: results of an international, randomized, double-blind, placebo- and active-controlled clinical trial performed in Europe. Eur Urol. 2011;59(3):342-352.

17. Denholm SW, Conn IG, Newsam JE, Chisholm GD. Morbidity following cystoscopy: comparison of flexible and rigid techniques. Br J Urol. 1990;66(2):152-154.

18. Hoffman RM, Monga M, Elliott SP, et al. Microwave thermotherapy for benign prostatic hyperplasia. Cochrane Database Syst Rev. 2012;12(9):CD004135.

19. Bouza C, López T, Magro A, Navalpotro L, Amate JM. Systematic review and meta-analysis of transurethral needle ablation in symptomatic benign prostatic hyperplasia. BMC Urol. 2006;21:14-31.

20. McVary KT, Gange SN, Gittelman MC, et al. Erectile and ejaculatory function preserved with convective water vapor energy treatment of LUTS secondary to BPH: randomized controlled study. J Sex Med. 2016;13(6):924-933.

21. Sorokin I, Schatz A, Welliver C. Placebo medication and sham surgery responses in benign prostatic hyperplasia treatments: Implications for clinical trials. Curr Urol Rep. 2015;169(10):73-83.

22. Welliver C, Kottwitz M, Feustel P, McVary K. Clinically and statistically significant changes seen in sham surgery arms of randomized, controlled benign prostatic hyperplasia surgery trials. J Urol. 2015;194(6):1682-1687.
Research and Reports in Urology

Publish your work in this journal

Research and Reports in Urology is an international, peer-reviewed, open access journal publishing original research, reports, editorials, reviews and commentaries on all aspects of adult and pediatric urology in the clinic and laboratory including the following topics: Pathology, pathophysiology of urological disease; Investigation and treatment of

\section{Dovepress}

urological disease; Pharmacology of drugs used for the treatment of urological disease. The manuscript management system is completely online and includes a very quick and fair peer-review system, which is all easy to use. Visit http://www.dovepress.com/testimonials.php to read real quotes from published authors. 